Pacific Journal of Mathematics

SUBDIRECT DECOMPOSITIONS OF LATTICES OF WIDTH
TWO 


\section{SUBDIRECT DECOMPOSITIONS OF LATTICES OF WIDTH TWO}

Oscar Tivis Nelson, JR.

The class of nontrivial distributive lattices is the class of subdirect products of two-element chains. Lattices of width one are distributive and hence are subdirect products of two element chains. Below it is shown that lattices of width two are subdirect products of two element chains and nonmodular lattices of order five $\left(N_{5}\right)$. (width $=$ greatest number of pairwise incomparable elements.)

The statement follows from several lemmas. Throughout we shall assume that $a, b$ are arbitrary noncomparable elements of a lattice $L$ of width two.

Lemma 1. $x \cdot(a+b)+y \cdot(a+b)=(x+y) \cdot(a+b)$ and

$$
(x+a \cdot b) \cdot(y+a \cdot b)=x \cdot y+a \cdot b
$$

for any $x, y \in L$.

Proof. In any lattice

$$
x \cdot(a+b)+y \cdot(a+b) \leqq(x+y) \cdot(a+b) \cdot
$$

Trivially, if $x$ and $y$ are related, the identity holds. Thus, assume that $x$ and $y$ are unrelated. There are three possibilities:

(i) Suppose $x \leqq a$ and $y \leqq b$. Then

$$
x \cdot(a+b)+y \cdot(a+b)=x+y=(x+y) \cdot(a+b) .
$$

(ii) In case $a \leqq x$ and $b \leqq y, a+b \leqq x+y$. If $a+b \leqq x$ or $y$, it is easy to verify that the identity holds. If $a+b \not \equiv x$ or $y$, then $x$ or $y \leqq a+b$. Suppose $x \leqq a+b$. Then

$$
(x+y) \cdot(a+b)=a+b \leqq x+y \cdot(a+b)=x \cdot(a+b)+y \cdot(a+b) .
$$

This relation and (1) yield the equality.

(iii) Now suppose $a \leqq x$ and $y \leqq b . b \leqq x$ implies that $x$ and $y$ are comparable while $x \leqq b$ implies that $a$ and $b$ are comparable. Thus, $x$ and $b$ are unrelated. Since $L$ is of width two, $a+y$ is related to either $x$ or $b, a+y \leqq x$ and $a+y \leqq b$ imply that $y \leqq x$ and $a \leqq b$ respectively. Thus, either $x \leqq a+y$ or $b \leqq a+y$. In case $x \leqq a+y, x \leqq a+y \leqq a+b$ and $y \leqq b \leqq a+b$. Hence

$$
x \cdot(a+b)+y \cdot(a+b)=x+y=(x+y)(a+b) .
$$


In case $b \leqq a+y, y \leqq b \leqq a+y \leqq a+b$. Thus,

$$
\begin{gathered}
(x+y) \cdot(a+b) \leqq a+b \leqq a+y \leqq x \cdot(a+b)+y \\
=x \cdot(a+b)+y \cdot(a+b)
\end{gathered}
$$

and the identity holds in all cases. A dual argument yields the other identity.

By Lemma 1, if $s$ and $t$ are unrelated elements of a lattice of width two, the mappings $x \rightarrow x \cdot(s+t)$ and $x \rightarrow x+s \cdot t$ determine congruence relations $\theta_{s+t}$ and $\psi_{s \cdot t}$.

LEMMA 2. $\theta_{a+b} \cap \psi_{a \cdot b}=0$.

Proof. If $x \equiv y\left(\theta_{a+b} \cap \psi_{a \cdot b}\right), x \cdot(a+b)=y \cdot(a+b)$ and $x+a \cdot b=$ $y+a \cdot b . x$ and $y$ are each related to either $a$ or $b$. Thus $x \leqq a+b$ or $a \cdot b \leqq x$. Similarly, $y \leqq a+b$ or $a \cdot b \leqq y$. If

$$
x, y \leqq a+b, x=x \cdot(a+b)=y \cdot(a+b)=y \text {. }
$$

If $a \cdot b \leqq x, y ; x=x+a \cdot b=y+a \cdot b=y$. Finally, if $x \leqq a+b$ and $a \cdot b \leqq y, a \cdot b \leqq y \cdot(a+b)=x \cdot(a+b)=x$, i.e., $a \cdot b \leqq x, y$ again. Thus $x=y$ in every case, and $\theta_{a+b} \cap \psi_{a \cdot b}=0$.

LEMma 3. If $\theta_{a+b}=0, a+b=1$; and if $\psi_{a \cdot b}=0, a \cdot b=0$.

Proof. By definition $x \cdot(a+b) \equiv x\left(\theta_{a+b}\right)$. Thus $\theta_{a+b}=0$ implies that

$$
x \cdot(a+b)=x
$$

for all $x$, and consequently that $a+b=1$. Similarly, $\psi_{a \cdot b}=0$ implies that $a \cdot b=0$.

Lemma 4. If $L$ is subdirectly irreducible, $\theta_{a+b}=0$, and $a \cdot b \neq 0$, then there exists $p \in L$ such that $p$ and $a \cdot b$ are noncomparable.

Proof. If $\theta_{a+b}=0, a \cdot b \neq 0$, and there exists no $p$ as above, than it is easy to verify that $\theta_{a \cdot b} \cap \psi_{a \cdot b}=0$. (Note that $x \equiv y\left(\theta_{a \cdot b}\right)$ if and only if $x=y$ or $a \cdot b \leqq x, y$, and that $x \equiv y\left(\psi_{a \cdot b}\right)$ if and only if $x=y$ or $x, y \leqq a \cdot b)$. Since $a \cdot b \neq 0$, neither $\theta_{a \cdot b}$ nor $\psi_{a \cdot b}=0$. Thus $L$ is reducible. This contradiction implies that $p$ must exist.

If $L$ and $p$ are as in Lemma $4, p$ must be related to $a$ or $b$, but $a \leqq p$ or $b \leqq p$ implies that $p$ and $a \cdot b$ are comparable. Thus we can assume that $p$ is less than one of $a, b$; assume $p<a$.

Lemma 5. If $L$ and $p$ are as in Lemma $4, p+a \cdot b$ and $b$ are 
noncomparable.

Proof. Clearly $a \cdot b \leqq b \cdot(p+a \cdot b)$. Since $p<a, p+a \cdot b \leqq a$, and hence $b \cdot(\mathrm{p}+a \cdot b) \leqq a \cdot b$. Thus $b \cdot(p+a \cdot b)=a \cdot b$. Since $a$ and $b$ are noncomparable, $a \cdot b \neq b$; and since $a \cdot b, p$ are noncomparable, $p+a \cdot b \neq a \cdot b$. Thus $b$ and $p+a \cdot b$ are noncomparable.

Lemma 6. If $L$ and $p$ are as in Lemma 4,

$$
L=\{x \mid x \leqq p+a \cdot b\} \cup\{x \mid a \cdot b \leqq x\} .
$$

Proof. Trivially, if $z$ is related to $a \cdot b, z$ is in one of the sets. Thus suppose that $z, a \cdot b$ are unrelated. Since $a \cdot b, p$ are noncomparable and $L$ is of width two, $z$ must be related to $p$. If $z \leqq p$, $z \leqq p+a \cdot b$. If $z$ is also related to $p+a \cdot b, z$ is in one of the sets. Thus, suppose that $p \leqq z$ and that $z$ and $p+a \cdot b$ are unrelated. By Lemma $5, p+a \cdot b$ and $b$ are unrelated. Thus, $z$ must be related to $b$. If $b \leqq z, a \cdot b \leqq z$; and if $z \leqq b, p \leqq z<b(p+a \cdot b \leqq b)$. But both conclusions are impossible. Thus $L$ is the union of the two sets.

Lemma 7. If $L$ and $p$ are as in Lemma $4, \theta_{p+a \cdot b} \cap \psi_{a \cdot b}=0$.

Proof. If $\quad x \equiv y\left(\theta_{p+a \cdot b} \cap \psi_{a \cdot b}\right), x \cdot(p+a \cdot b)=y \cdot(p+a \cdot b)$ and $x+a \cdot b=y+a \cdot b$. If

$$
x, y \leqq p+a \cdot b, x=x \cdot(p+a \cdot b)=y \cdot(p+a \cdot b)=y ;
$$

and if $a \cdot b \leqq x, y, x=x+a \cdot b=y+a \cdot b=y$. Thus suppose

$$
x \leqq p+a \cdot b
$$

and $a \cdot b \leqq y$ (By Lemma 6, we can assume that this is the only remaining possibility.) Then $x=x \cdot(p+a \cdot b)=y \cdot(p+a \cdot b) \leqq y$, i.e., $x \leqq y$. Also, $x+a \cdot b=y+a \cdot b=y$. Since

$$
x \leqq p+a \cdot b, y=x+a \cdot b \leqq p+a \cdot b .
$$

Thus, $x \leqq y \leqq p+a \cdot b$, and $x=x \cdot(p+a \cdot b)=y \cdot(p+a \cdot b)=y$.

LEMMA 8. If $L$ is a subdirectly irreducible lattice of width two and $a, b$ are noncomparable elements of $L, a+b=1$ and $a \cdot b=0$.

Proof. By Lemma 2, $\theta_{a+b} \cap \psi_{a \cdot b}=0$. Since $L$ is irreducible, $\theta_{a+b}=0$ or $\psi_{a \cdot b}=0$. Suppose $\theta_{a+b}=0$. Then $a+b=1$ by Lemma 3. If $a \cdot b \neq 0, \psi_{a \cdot b} \neq 0$ by Lemma 3. Also, by Lemma 4 , there is an element $p$ of $L$ which is noncomparable to $a \cdot b$. For this $p$, 


$$
\theta_{p+a \cdot b} \cap \psi_{a \cdot b}=0
$$

by Lemma 7. Hence $\theta_{p+a \cdot b}=0$. But this is impossible since it implies that $1=p+a \cdot b \leqq a$ or $b$. Hence $a \cdot b=0$. If $\psi_{a \cdot b}=0$, a dual argument completes the proof.

(Note that Lemma 8 implies that a subdirectly irreducible lattice of width two has a zero and a one.)

Let $L$ be a subdirectly irreducible lattice of width two. If there were an element $z$ of $L-\{0,1\}$ which was comparable to each element of $L, \theta_{z} \cap \psi_{z}=0$ with $\theta_{z} \neq 0$ and $\psi_{z} \neq 0$. Thus, since $L$ is irreducible, it must be the union of the pairwise disjoint sets $\{0,1\}, C_{1}, C_{2}$ where $C_{1}, C_{2}$ are chains such that the sum of elements from different chains is 1 and the product, 0 . If each chain has at least two elements, then one can define two congruence relations $R_{1}, R_{2}$ as follows:

$x \equiv y\left(R_{i}\right)$ if and only if $x=y$ or $x, y \in C_{i}(i=1,2)$. Clearly, $R_{1} \cap R_{2}=0$, but $R_{1}, R_{2} \neq 0$ since each chain contains at least two elements. Thus, one chain must contain exactly one element. If both chains consist of a single element, $L$ is a direct product of twoelement chains, and hence is reducible. Thus, $L$ consists of $\{0,1\}$, $C_{1}, C_{2}$ where $C_{1}$ contains only one element and $C_{2}$ contains at least two elements. Suppose $C_{2}$ contains at least three elements $p<q<r$. Define relations $S_{1}, S_{2}$ on $L$ by

$$
\begin{aligned}
& x \equiv y\left(S_{1}\right) \text { if and only if } x=y \text { or } 0<x, y \leqq q \\
& x \equiv y\left(S_{2}\right) \text { if and only if } x=y \text { or } q \leqq x, y<1 .
\end{aligned}
$$

It is easy to show that these are congruence relations. Clearly $S_{1} \cap S_{2}=0$. Thus $S_{1}=0$ or $S_{2}=0$. But $p \equiv q\left(S_{1}\right)$ and $q \equiv r\left(S_{2}\right)$, a contradiction. Thus $C_{2}$ consists of exactly two elements, and $L \cong N_{5}$. Hence

THEOREM. Every lattice of width two is a subdirect product of two-element chains and $N_{5}$.

COROLlaRY. The only subdirectly irreducible lattice of width two is $N_{5}$.

For each $n \geqq 3$, one can exhibit a lattice to show that it is false that all lattices of width $n$ are subdirect products of lattices from some class of finite lattices. For a fixed $n$, it would be of interest to find a lattice property $P$ such that if $L$ were of width $n$ and had property $P$, that $L$ would be a subdirect product of finite lattices. 


\section{REFERENCES}

1. G. Birkhoff, Lattice Theory, Amer. Math. Soc. Colloquium Publications, Vol. 25, 1948 (rev. ed.).

2. - Subdirect unions in universal algebras, Bull. Amer. Math. Soc. 50 (1944) 764-768.

Received January 16, 1967.

EMORY UNIVERSITY 



\section{PACIFIC JOURNAL OF MATHEMATICS}

\section{EDITORS}

\author{
H. ROYDEN \\ Stanford University \\ Stanford, California
}

\author{
J. P. JANS \\ University of Washington \\ Seattle, Washington 98105
}

J. DugundJI

Department of Mathematics

Rice University

Houston, Texas 77001

RICHARD ARENS

University of California

Los Angeles, California 90024

\section{ASSOCIATE EDITORS}
E. F. BECKENBACH
B. H. NeumanN
F. WOLF
K. YOSIDA

\section{SUPPORTING INSTITUTIONS}

\author{
UNIVERSITY OF BRITISH COLUMBIA \\ CALIFORNIA INSTITUTE OF TECHNOLOGY \\ UNIVERSITY OF CALIFORNIA \\ MONTANA STATE UNIVERSITY \\ UNIVERSITY OF NEVADA \\ NEW MEXICO STATE UNIVERSITY \\ OREGON STATE UNIVERSITY \\ UNIVERSITY OF OREGON \\ OSAKA UNIVERSITY \\ UNIVERSITY OF SOUTHERN CALIFORNIA
}

\author{
STANFORD UNIVERSITY \\ UNIVERSITY OF TOKYO \\ UNIVERSITY OF UTAH \\ WASHINGTON STATE UNIVERSITY \\ UNIVERSITY OF WASHINGTON \\ AMERICAN MATHEMATICAL SOCIETY \\ CHEVRON RESEARCH CORPORATION \\ TRW SYSTEMS \\ NAVAL ORDNANCE TEST STATION
}

\footnotetext{
Mathematical papers intended for publication in the Pacific Journal of Mathematics should be in typed form or offset-reproduced, double spaced with large margins. Underline Greek letters in red, German in green, and script in blue. The first paragraph or two must be capable of being used separately as a synopsis of the entire paper. It should not contain references to the bibliography. Manuscripts may be sent to any one of the four editors. All other communications to the editors should be addressed to the managing editor, Richard Arens, University of California, Los Angeles, California 90024.

Each author of each article receives 50 reprints free of charge; additional copies may be obtained at cost in multiples of 50 .

The Pacific Journal of Mathematics is published monthly. Effective with Volume 16 the price per volume (3 numbers) is $\$ 8.00$; single issues, $\$ 3.00$. Special price for current issues to individual faculty members of supporting institutions and to individual members of the American Mathematical Society: $\$ 4.00$ per volume; single issues $\$ 1.50$. Back numbers are available.

Subscriptions, orders for back numbers, and changes of address should be sent to Pacific Journal of Mathematics, 103 Highland Boulevard, Berkeley 8, California.

Printed at Kokusai Bunken Insatsusha (International Academic Printing Co., Ltd.), 7-17, Fujimi 2-chome, Chiyoda-ku, Tokyo, Japan.

PUBLISHED BY PACIFIC JOURNAL OF MATHEMATICS, A NON-PROFIT CORPORATION

The Supporting Institutions listed above contribute to the cost of publication of this Journal, but they are not owners of publishers and have no responsibility for its content or policies.
} 


\section{Pacific Journal of Mathematics}

\section{Vol. 24, No. $3 \quad$ July, 1968}

Duane W. Bailey, On symmetry in certain group algebras ............ 413

Lawrence Peter Belluce and Surender Kumar Jain, Prime rings with a one-sided ideal satisfying a polynomial identity ................ 421

L. Carlitz, A note on certain biorthogonal polynomials ............. 425

Charles O. Christenson and Richard Paul Osborne, Pointlike subsets of a manifold ......................................... 431

Russell James Egbert, Products and quotients of probabilistic metric

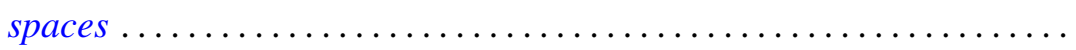

Moses Glasner, Richard Emanuel Katz and Mitsuru Nakai, Bisection into small annuli ..................................... 457

Karl Edwin Gustafson, A note on left multiplication of semigroup

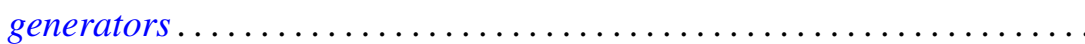

I. Martin (Irving) Isaacs and Donald Steven Passman, A characterization of groups in terms of the degrees of their characters. II ............. 467

Howard Wilson Lambert and Richard Benjamin Sher, Point-like

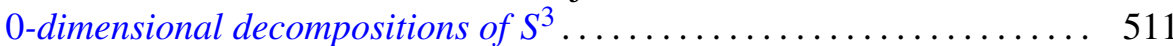

Oscar Tivis Nelson, Subdirect decompositions of lattices of width two ..... 519

Ralph Tyrrell Rockafellar, Integrals which are convex functionals . . . . . . . 525

James McLean Sloss, Reflection laws of systems of second order elliptic differential equations in two independent variables with constant coefficients ...

Bui An Ton, Nonlinear elliptic convolution equations of Wiener-Hopf type in a bounded region

Daniel Eliot Wulbert, Some complemented function spaces in $C(X)$

Zvi Ziegler, On the characterization of measures of the cone dual to a generalized convexity cone. 